\title{
Cross-autocorrelations in European stock returns
}

\author{
Amado Peiró* \\ Department d'Anàlisi Econòmica, Universitat de València, Spain
}

Received: 6 November 2015

Revised: 10 March 2016

Accepted: 5 May 2016

\begin{abstract}
This paper examines lead-lag relationships between monthly index returns from 18 European industries. Several interesting and clear relationships are found that call into question the efficiency of European stock markets. While the Automobiles \& Parts sector lags more than half of the other sectors, the Financial Services, Technology, and Telecommunications sectors lead many others. In particular, the leadership of the Technology sector has strengthened in recent years.
\end{abstract}

Keywords: cross-autocorrelations; efficient markets; European stock markets; sector indices JEL Classification Codes: G12

\section{Introduction}

Autocorrelation tests in stock or index returns are among the most widely used tests in the examination of stock market efficiency. The empirical evidence is overwhelming. In terms of stock index returns, the main conclusions to be drawn are that although autocorrelations may be statistically significant in some cases, they are not large and, consequently, are economically insignificant or of very limited economic importance. Thus, Fama and French (1988) find negative first-order autocorrelations for long-horizon returns from US industry portfolios with a Ushaped pattern: they 'become negative for 2-year returns, reach minimum values for 3-5-year returns, and then move back toward 0.0 for longer return horizons'. Poterba and Summers (1988) find positive autocorrelation in index returns over short horizons and negative autocorrelation over longer horizons. Lo and MacKinlay $(1988,1990)$ find positive and significant first-order autocorrelation for weekly returns from US market indices. In their influential book, Campbell et al. (1996) report that autocorrelations of daily, weekly and monthly stock index returns are positive and statistically significant at the first lag.

\footnotetext{
*E-mail: amado.peiro@uv.es.

Citation: Peiró, A. (2016) Cross-autocorrelations in European stock returns, Economics and Business Letters, 5(1), 30-37.
} 
There has been far less analysis of cross-correlations in index returns, with most contributions aiming to study the relationships among international stock markets rather than the relationships among different industries or sectors. In a seminal paper, Lo and MacKinlay (1990) showed that large stocks lead small stocks. Ewing (2002) examines five major S\&P indices and concludes that shocks to an index can account for much of the fluctuation in other indices. Hong et al. (2007) find that the returns of a significant number of US industry portfolios can be used to forecast the movements of the stock market and, furthermore, similar results are obtained for other non-US markets. Kong et al. (2009) find that different industry portfolios present different predictability when considering a variety of economic variables and lagged industry returns as predictors. Menzly and Ozbas (2010) find evidence that industry-level returns are predictable based on lagged returns in supplier and customer industries.

The existence of auto- or dynamic cross-correlations is a very important issue as it would imply the predictability of future returns and could call into question the efficiency of these markets. If past returns forecast future returns, prices would not fully reflect all available information and, therefore, the market would not be efficient, according to the traditional definition of efficient capital markets proposed by Fama (1970). Two main types of explanations have been proposed for the existence of auto- and cross-correlations of stock index returns (see, for example, Mech, 1993, Chordia et al. 2007, or Anderson et al. 2012). Firstly, such correlations have been attributed to the market microstructure, and in particular to nonsynchronous trading effects. Secondly, they have also been attributed to a partial adjustment of stock prices to new information. It is evident that nonsynchronous trading may cause auto- and cross-correlation in index returns, but the question is whether it can completely explain these phenomena. Anderson et al. (2012) find compelling evidence that partial adjustment is a major source of autocorrelation. With regard to cross-autocorrelation, Chordia et al. (2007) find that common informational events impact the large-cap sector first, causing large-cap spreads to widen, and are subsequently incorporated with a lag into the prices of small-cap stocks. Bernhardt and Davies (2008) examine 24-hour portfolio returns and find that nonsynchronous trading 'explains only a moderate fraction of differences in portfolio cross-autocorrelations', typically between $5 \%$ and $12 \%$.

This paper documents significant cross-autocorrelations among stock index returns in European markets. Eighteen industry indices that include companies from different European countries are examined, and it is found that clear lead-lag patterns exist between different sectors and, moreover, nonsynchronous trading cannot fully explain these relationships. To this end, Section 2 presents the data used in this study, Section 3 reports evidence on the dynamic relationships among sector index returns and, finally, Section 4 summarizes the main conclusions.

\section{Data}

Eighteen Stoxx sector indices were available for the Eurozone. Using the market standard Industry Classification Benchmark (ICB), companies are categorized according to their primary source of revenue into 18 supersectors: Automobiles \& Parts, Banks, Basic Resources, Chemicals, Construction \& Materials, Financial Services, Food \& Beverage, Industrial Goods \& Services, Insurance, Media, Oil \& Gas, Personal \& Household Goods, Real Estate, Retail, Technology, Telecommunications, Travel \& Leisure, and Utilities. Table 1 shows these different sectors and their sample periods. Though these indices were available on a daily basis, the analysis that follows is carried out on a monthly basis. The reason for this lies in the fact that these indices cover a long time span and include many companies from different European countries, whose stock markets may have different trading hours. News reaching a particular market open for trade may not be incorporated into other markets' stock prices until the following day if these markets were closed when the information reached the first market. This would cause a 
problem of nonsynchronous trading that could affect the dynamic cross-correlations between the returns of the different indices. This could be a serious problem if using daily indices, as they include companies that are from markets with different trading times; however, with monthly returns this problem is largely or entirely eliminated. ${ }^{1}$ Consequently, in order to avoid or minimize nonsynchronous trading effects, the analysis will be carried out on a monthly basis. Monthly returns were obtained by logarithmic differences; that is by $R_{t}=\log \left(I_{t}\right)-\log \left(I_{t-1}\right)$ where $R_{t}$ is the return for month $t$ and $I_{t}$ is the index for the same month.

Table 1. Euro Stoxx supersector indices with the number of their component companies.

\begin{tabular}{lcccc}
\hline \hline Supersector Index & Symbol & Name & Components & Sample \\
\hline \hline Automobiles \& Parts & SXAE & AP & 14 & $1987-2015$ \\
\hline Banks & SX7E & BK & 30 & $1987-2015$ \\
\hline Basic Resources & SXPE & BR & 7 & $1987-2015$ \\
\hline Chemicals & SX4E & CH & 16 & $1987-2015$ \\
\hline Construction \& Materials & SXOE & CM & 11 & $1987-2015$ \\
\hline Financial Services & SXFE & FS & 7 & $1987-2015$ \\
\hline Food \& Beverage & SX3E & FB & 11 & $1987-2015$ \\
\hline Industrial Goods \& Services & SXNE & IG & 47 & $1987-2015$ \\
\hline Insurance & SXIE & IN & 15 & $1987-2015$ \\
\hline Media & SXME & ME & 18 & $1987-2015$ \\
\hline Oil \& Gas & SXEE & OG & 11 & $1987-2015$ \\
\hline Personal \& Household Goods & SXQE & PG & 14 & $1992-2015$ \\
\hline Real Estate & SX86E & RE & 12 & $2001-2015$ \\
\hline Retail & SXRE & RT & 11 & $1992-2015$ \\
\hline Technology & SX8E & TE & 16 & $1987-2015$ \\
\hline Telecommunications & SXKE & TC & 12 & $1987-2015$ \\
\hline Travel \& Leisure & SXTE & TL & 7 & $1991-2015$ \\
\hline Utilities & SX6E & UT & 18 & $1987-2015$ \\
\hline \hline
\end{tabular}

Note: In all cases the sample period begins in January and ends in February of the years indicated in the last column.

Table 2. First-order autocorrelations of monthly returns of the different indices.

\begin{tabular}{lccccccccc}
\hline \hline & $A P$ & $B K$ & $B R$ & $C H$ & $C M$ & $F S$ & $F B$ & $I G$ & $I N$ \\
\hline Whole sample & 0,05 & $0.15^{* *}$ & $0.19^{* *}$ & 0.06 & $0.12^{*}$ & $0.22^{* *}$ & $0.12^{*}$ & $0.16^{* *}$ & 0.03 \\
\hline 2000:01-2015:02 & -0.03 & $0.15^{*}$ & $0.18^{*}$ & 0.07 & 0.12 & $0.21^{* *}$ & 0.10 & 0.12 & -0.01 \\
\hline \hline & $M E$ & $O G$ & $P G$ & $R E$ & $R T$ & $T E$ & $T C$ & $T L$ & $U T$ \\
\hline Whole sample & $0.16^{* *}$ & 0.05 & 0.04 & $0.26^{* *}$ & 0.10 & $0.15^{* *}$ & $0.14^{* *}$ & 0.03 & 0.10 \\
\hline 2000:01-2015:02 & 0.09 & 0.04 & 0.09 & $0.26^{* *}$ & 0.14 & 0.09 & 0.03 & 0.01 & 0.08 \\
\hline \hline
\end{tabular}

Note: $*(* *)$ denotes significant at the $5 \%(1 \%)$ level.

\section{Cross-correlations in index returns}

Table 2 shows the first-order autocorrelation of monthly returns for the different indices. Two main conclusions can be drawn from this table. Firstly, many autocorrelations are clearly significant. This is in line with previous research outlined in Section 1. Given the evidence reported by Chordia et al. (2007) and Anderson et al. (2012), it could, to some extent, be due to a partial adjustment of stock prices to the arrival of new information. Secondly, the autocorrelations are

\footnotetext{
${ }^{1}$ As suggested by a referee, a common trading window would provide a solution to this problem and would allow the use of higher-frequency information. However, this solution was not possible with the available data.
} 
weaker in recent years. While in the whole period eight autocorrelations were significant at the 1\% level, only two of them are significant at this same level in the period 2000:01-2015:02.

All the contemporaneous cross-correlations are positive, ranging between 0.25 and 0.89 , and all of them are clearly significant, but this is hardly surprising as the different industries are exposed to common factors. It is much more interesting to analyse the dynamic cross-correlations. Given the existence of first-order autocorrelation in index returns, in order to examine their dynamic cross-correlations the following regressions have been estimated:

$$
R_{i, t}=\alpha+\sum_{k=1}^{m} \beta_{k} R_{j, t-k}+\sum_{p=1}^{n} \gamma_{p} R_{i, t-p}+u_{i, t}
$$

where $R_{i, t}$ and $R_{j, t}$ denote returns in stock indices $i$ and $j$ in month $t$, respectively, $m \geq 1$ and $n \geq 1$. The regressors $R_{i, t-p}$ have been included to control for the effect of autocorrelation. In an overwhelming majority of the regressions the parameters $\beta_{2}, \beta_{3}, \ldots, \beta_{m}$ were not significant. However, the situation is very different with regard to the parameter $\beta_{1}$. Table 3 reports the estimates for $\beta_{1}$ for the different indices with $m=n=3$. The results obtained are very similar for other possible values of $m$ and $n$, as fixing $n=1$ (first-lag autocorrelation) captures almost all the autocorrelation structure, and fixing $m=1$ (first-order dynamic cross-correlation) captures almost all the dynamic cross-correlation structure.

Table 3 shows many more significant estimates than expected $-18 \%$ of all the estimates are significant at the $5 \%$ significance level, and $6 \%$ at the $1 \%$ level- which suggests significant relationships among the different sectors. Nevertheless, they are not scattered uniformly but rather are more concentrated in some sectors than in others. Looking at the results by industry, two main conclusions follow. Firstly, all the estimates in the regressions for the sector Automobiles \& Parts (column AP) are positive and many of them are statistically significant, with 10 out of 17 significant at the 5\% significance level and 4 of those at the $1 \%$ level. Therefore, it seems clear that this sector reacts with a one-month delay to the fluctuations in other sectors. Secondly, the estimates accompanying the first lag of the Financial Services, Technology, and Telecommunications sectors (rows FS, TE and TC, respectively) are significant very often. The sector FS is significant in 10 out of 17 cases at the $5 \%$ level and 3 of those are significant at the $1 \%$ level. The sector TE is significant in eight cases at the 5\% level and in four at the $1 \%$ level. Finally, the sector TC is significant in nine cases at the 5\% level and in two at the $1 \%$ level. Moreover, there is no lead-lag relationship at all between these three sectors. Consequently, there is strong evidence that these three sectors lead the other sectors with a one-month delay.

The sample periods are relatively long, and one could question whether these features hold over the whole period or if, on the contrary, they change over time with possible structural breaks. Rolling regressions with overlapping sample periods could help to provide some insight into this issue. As an example, let us reconsider the first significant regression at the $1 \%$ level in Table 3. Figure 1 shows the estimates of $\beta_{1}$ in rolling regressions of AP returns on FS returns. In these regressions the sample sizes are five years of monthly returns. ${ }^{2}, 1987: 01-1991: 12$, 1987:02-1992:01 , .., 2010:03-2015:02. There are two important points to bear in mind. Firstly, an overwhelming majority of estimates are positive, as a result of which the estimate in the whole period is significantly positive. Secondly, the estimates in the later years are clearly higher than in the early years, and, furthermore, they are very often significant, in sharp contrast with the estimates from the first years.

\footnotetext{
${ }^{2}$ Other sample sizes yielded similar conclusions.
} 
Table 3. Estimates of $\beta_{1}$ in the regressions $R_{i, t}=\alpha+\sum_{k=1}^{3} \beta_{k} R_{j, t-k}+\sum_{p=1}^{3} \gamma_{p} R_{i, t-p}+u_{i, t}$, where $R_{i}$ is the return on the index indicated in the headings of the column, and $R_{j}$ is the return on the index indicated in the row.

\begin{tabular}{|c|c|c|c|c|c|c|c|c|c|c|c|c|c|c|c|c|c|c|}
\hline & $A P$ & $B K$ & $B R$ & $\mathrm{CH}$ & $C M$ & $F S$ & $F B$ & $I G$ & $I N$ & $M E$ & $O G$ & $P G$ & $R E$ & $R T$ & $T E$ & $T C$ & $T L$ & $U T$ \\
\hline$A P$ & - & -0.09 & -0.05 & 0.00 & 0.00 & -0.07 & 0.05 & -0.06 & -0.07 & $-0.13 *$ & 0.02 & -0.06 & -0.10 & -0.07 & $-0.21 * *$ & -0.09 & 0.05 & -0.03 \\
\hline$B K$ & $0.19 *$ & - & 0.10 & 0.12 & 0.09 & -0.01 & 0.04 & 0.03 & 0.15 & -0.10 & 0.07 & 0.06 & 0.08 & 0.01 & -0.14 & -0.12 & 0.12 & 0.05 \\
\hline$B R$ & 0.07 & 0.04 & - & 0.12 & 0.02 & -0.09 & 0.03 & 0.07 & 0.00 & -0.06 & 0.05 & 0.03 & 0.04 & -0.01 & -0.06 & -0.06 & 0.01 & 0.02 \\
\hline $\mathrm{CH}$ & 0.19 & 0.00 & -0.01 & - & 0.00 & -0.08 & 0.01 & -0.02 & 0.05 & $-0.16^{*}$ & 0.05 & 0.10 & 0.03 & -0.05 & -0.12 & -0.09 & 0.10 & 0.03 \\
\hline$C M$ & $0.22 *$ & 0.03 & 0.14 & 0.15 & - & -0.03 & 0.08 & 0.03 & 0.14 & $-0.20 *$ & $0.13^{*}$ & 0.12 & 0.07 & 0.00 & -0.14 & -0.10 & 0.11 & 0.08 \\
\hline$F S$ & $0.34 * *$ & 0.13 & $0.22 *$ & $0.19 *$ & $0.29 * *$ & - & 0.11 & $0.18^{*}$ & $0.35 * *$ & -0.04 & $0.13^{*}$ & $0.19 *$ & 0.08 & 0.12 & -0.06 & -0.06 & $0.24 *$ & $0.13^{*}$ \\
\hline$F B$ & $0.23^{*}$ & -0.02 & -0.02 & 0.09 & 0.01 & -0.04 & - & -0.04 & 0.07 & -0.11 & 0.04 & 0.12 & -0.05 & 0.08 & 0.00 & -0.06 & 0.08 & 0.04 \\
\hline$I G$ & $0.28 * *$ & 0.09 & 0.12 & $0.26 * *$ & 0.11 & 0.02 & $0.12 *$ & - & $0.20^{*}$ & -0.17 & 0.10 & $0.24 *$ & 0.09 & 0.03 & -0.15 & -0.10 & 0.12 & 0.09 \\
\hline$I N$ & $0.15^{*}$ & -0.08 & -0.01 & 0.06 & 0.03 & -0.10 & 0.02 & 0.03 & - & -0.06 & 0.02 & 0.07 & 0.06 & 0.01 & -0.14 & -0.11 & 0.05 & 0.02 \\
\hline$M E$ & 0.10 & 0.03 & 0.05 & 0.12 & 0.08 & -0.01 & 0.07 & 0.11 & $0.22 * *$ & - & $0.11 *$ & 0.10 & 0.07 & 0.07 & -0.08 & 0.01 & 0.06 & $0.16^{* *}$ \\
\hline$O G$ & 0.10 & 0.05 & 0.05 & 0.15 & -0.03 & 0.01 & 0.04 & -0.03 & 0.07 & $-0.22 * *$ & - & 0.03 & -0.17 & -0.10 & -0.09 & -0.13 & 0.03 & 0.00 \\
\hline$P G$ & 0.21 & 0.00 & -0.05 & 0.03 & -0.03 & -0.03 & 0.05 & -0.05 & 0.07 & -0.12 & 0.01 & - & 0.04 & -0.03 & $-0.32 * *$ & -0.16 & 0.02 & 0.03 \\
\hline$R E$ & $0.28^{*}$ & 0.30 & 0.24 & $0.23^{*}$ & 0.18 & 0.21 & 0.14 & 0.08 & $0.36^{* *}$ & -0.06 & $0.26^{* *}$ & 0.12 & - & 0.13 & -0.04 & -0.06 & 0.22 & $0.19 *$ \\
\hline$R T$ & 0.20 & -0.04 & 0.06 & 0.07 & 0.03 & -0.06 & 0.02 & 0.01 & 0.15 & -0.11 & 0.04 & 0.11 & 0.01 & - & $-0.25^{*}$ & -0.07 & 0.03 & 0.03 \\
\hline$T E$ & $0.18^{*}$ & 0.07 & $0.14 *$ & $0.13 * *$ & 0.10 & 0.01 & 0.05 & $0.24 * *$ & $0.19 * *$ & 0.10 & $0.09 *$ & $0.19 * *$ & 0.06 & 0.09 & - & 0.04 & $0.15^{*}$ & 0.07 \\
\hline$T C$ & $0.20 * *$ & 0.05 & 0.12 & $0.12 *$ & $0.14 *$ & 0.01 & 0.03 & $0.16^{* *}$ & $0.16^{*}$ & $0.15 *$ & $0.09 *$ & $0.11 *$ & 0.08 & 0.07 & 0.07 & - & 0.11 & $0.11 *$ \\
\hline$T L$ & $0.25 * *$ & -0.04 & 0.03 & 0.10 & 0.06 & -0.02 & $0.10^{*}$ & 0.07 & 0.06 & -0.03 & 0.08 & 0.13 & 0.04 & 0.02 & -0.13 & -0.07 & - & 0.01 \\
\hline$U T$ & 0.19 & -0.04 & 0.15 & 0.12 & 0.09 & -0.02 & 0.05 & 0.06 & 0.20 & -0.12 & 0.10 & 0.09 & 0.07 & -0.09 & -0.08 & -0.09 & 0.03 & - \\
\hline
\end{tabular}

Note: *(**) denotes significant at the $5 \%(1 \%)$ level.

Table 5. Estimates of $\beta_{1}$ in the regressions $R_{i, t}=\alpha+\sum_{k=1}^{3} \beta_{k} R_{j, t-k}+\sum_{p=1}^{3} \gamma_{p} R_{i, t-p}+u_{i, t}$, where $R_{i}$ is the return on the index indicated in the headings of the column and $R_{j}$ is the return on the index indicated in the row.

\begin{tabular}{ccccccccccccccccccc}
\hline \hline & $A P$ & $B K$ & $B R$ & $C H$ & $C M$ & $F S$ & $F B$ & $I G$ & $I N$ & $M E$ & $O G$ & $P G$ & $R E$ & $R T$ & $T E$ & $T C$ & $T L$ & $U T$ \\
\hline$F S$ & $0.30^{*}$ & 0.15 & 0.27 & $0.24^{*}$ & $0.29^{*}$ & - & 0.11 & 0.20 & $0.45^{* *}$ & -0.04 & $0.20^{*}$ & 0.18 & 0.08 & 0.13 & -0.18 & -0.17 & 0.24 & $0.18^{*}$ \\
\hline$T E$ & $0.20^{*}$ & 0.10 & 0.14 & $0.14^{*}$ & 0.10 & 0.07 & $0.09^{*}$ & $0.30^{* *}$ & $0.26^{* *}$ & $0.20^{*}$ & $0.13^{* *}$ & $0.23^{* *}$ & 0.06 & 0.11 & - & 0.03 & $0.17^{*}$ & $0.12^{*}$ \\
\hline$T C$ & $0.27^{* *}$ & 0.03 & 0.11 & $0.15^{*}$ & 0.13 & 0.02 & 0.06 & $0.21^{*}$ & 0.17 & $0.24^{*}$ & $0.12^{*}$ & 0.13 & 0.08 & 0.07 & 0.03 & - & 0.07 & $0.16^{*}$ \\
\hline \hline
\end{tabular}

Note: * (**) denotes significant at the 5\% (1\%) level. The sample period is 2000:01 - 2015:02. 
Figure 1. Estimates of $\beta_{1}$ in the rolling regressions $R_{i, t}=\alpha+\sum_{k=1}^{3} \beta_{k} R_{j, t-k}+\sum_{p=1}^{3} \gamma_{p} R_{i, t-p}+u_{i, t}$, where $R_{i}$ is the return on the Automobiles \& Parts index (AP) and $R_{j}$ is the return on the Financial Services index (FS).

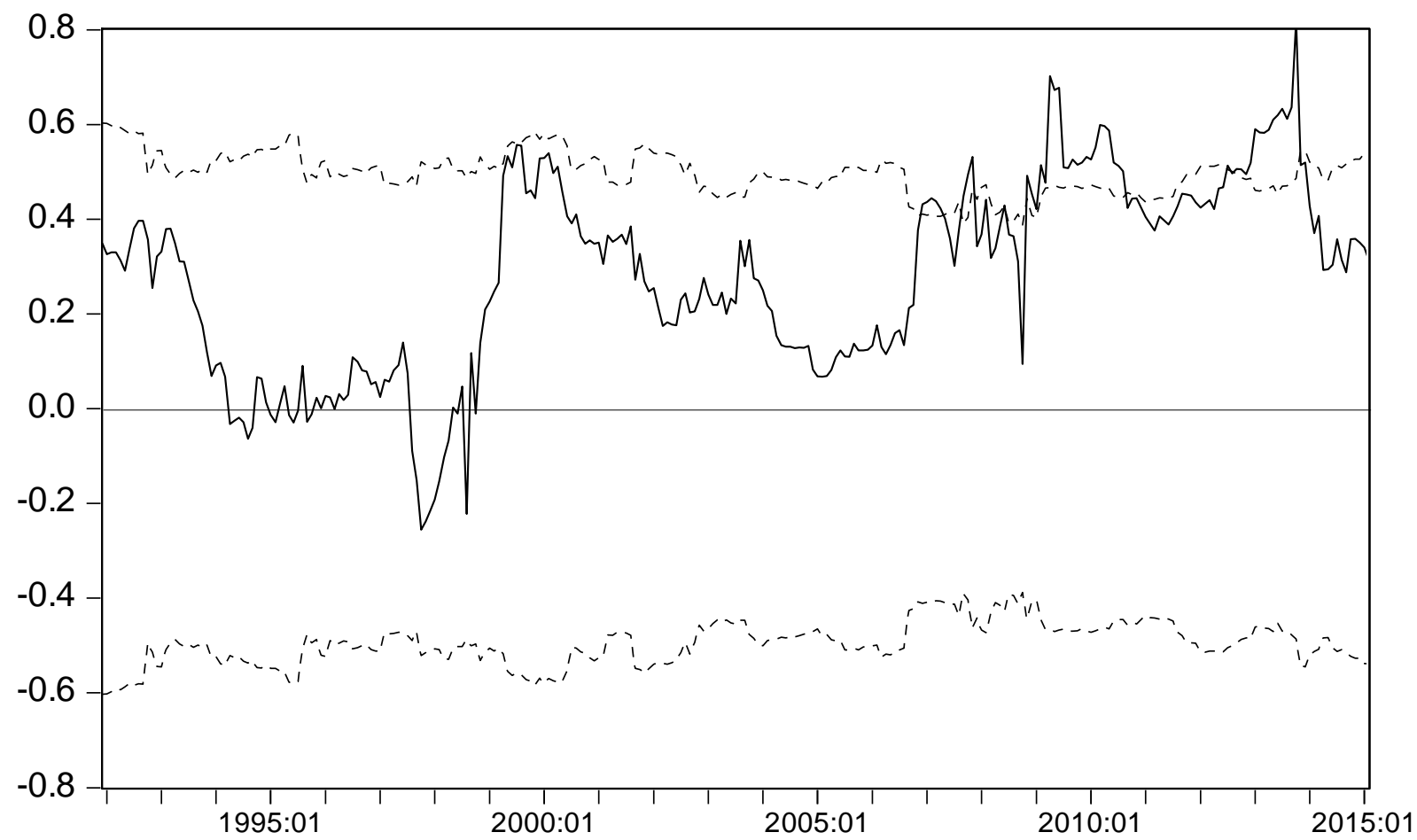

Note: The rolling samples are: 1987:01-1991:12, 1987:02-1992:01, .., 2010:03-2015:02. The date on the x-axis indicates the last date of the corresponding regression. The dotted lines are drawn at plus/minus two standard errors.

Table 4. Estimates of $\beta_{1}$ in the regressions $R_{i, t}=\alpha+\sum_{k=1}^{3} \beta_{k} R_{j, t-k}+\sum_{p=1}^{3} \gamma_{p} R_{i, t-p}+u_{i, t}$, where $\mathrm{R}_{\mathrm{i}}$ is the return on the index AP and $\mathrm{R}_{\mathrm{j}}$ is the return on the index indicated in the different headings.

\begin{tabular}{ccccccccc}
\hline \hline $\mathrm{AP}$ & BK & BR & CH & CM & FS & FB & IG & IN \\
\hline- & $0.24^{*}$ & 0.06 & 0.20 & 0.22 & $0.30^{*}$ & 0.13 & $0.27^{*}$ & 0.17 \\
\hline \hline ME & OG & PG & RE & RT & TE & TC & TL & UT \\
\hline 0.10 & 0.00 & 0.20 & $0.28^{*}$ & 0.26 & $0.20^{*}$ & $0.27^{* *}$ & 0.22 & 0.13 \\
\hline \hline
\end{tabular}

Note: * $(* *)$ denotes significant at the 5\% (1\%) level. The sample period is 2000:01 - 2015:02.

For reasons of space, a detailed discussion of the rolling regressions for the different sectors is not possible, but two features similar to those outlined above emerge in many cases: the estimates are mostly positive, and they present substantial variability over time. Given this evidence and that previously reported with regard to the autocorrelations, it is worth asking whether the results presented in Table 3 hold in recent years. Table 4 and 5 show the results obtained for these sectors in the period 2000:01-2015:02. The sensitivity of the sector AP has decreased: from ten to six significant relationships at the 5\% level. The leadership of the sectors FS and TC seem to have decreased somewhat in recent years: from ten to six and from nine to six significant relationships, respectively. On the contrary, the leadership of the TE sector has increased in recent years. While there are eight significant relationships over the whole period, in the 2000-2015 period there are ten significant leaderships; this means that more than half the sectors follow the movements in the TE sector. 
The surprising results reported above are not attributable to factors such as nonsynchronous trading, as all these indices are composed of large companies and monthly returns have been used. They call into question the efficiency of European stock markets. In addition, they pave the way for interesting research lines and projects that should address the following questions: Are these significant cross-correlations exclusively due to partial adjustment of stock prices? How great is the magnitude of return cross-predictability? How do these relationships evolve over the different market conditions and phases? All these questions are important areas for future research.

\section{Conclusions}

This paper examines the dynamic cross-correlations between monthly returns from 18 indices. These indices are composed of European large companies from different sectors. It is found that first-lag cross-correlations are very often significant. These results are due to the sensitivity of industries such as Automobiles \& Parts (AP) to the immediately preceding movements in other industries or to the leadership of industries such as Financial Services, Technology and Telecommunications (FS, TE and TC, respectively). These relationships have weakened somewhat in recent years, but the leadership of the TE sector has strengthened.

Acknowledgements. I wish to thank an anonymous referee for useful comments and suggestions.

\section{References}

Anderson, R.M., Eom, K.S., Hahn, S.B. and Park, J. (2012) Sources of stock return autocorrelation (working paper), Department of Economics, University of California at Berkeley.

Bernhardt, D. and Davies, R.J. (2008) The impact of nonsynchronous trading on differences in portfolio cross-autocorrelations (working paper), UNSW Business School.

Campbell, J.Y., Lo, A.W. and MacKinlay, A.W. (1996) The Econometrics of Financial Markets, Princeton University Press, NJ.

Chordia, T., Sarkar, A. and Subrahmanyam, A. (2007) The microstructure of crossautocorrelations (staff report no. 303), Federal Reserve Bank of New York.

Ewing, B.T. (2002) The transmission of shocks among S\&P indexes, Applied Financial Economics, 12, 285-290.

Fama, E.F. (1970) Efficient capital markets: A review of theory and empirical work, Journal of Finance, 25, 383-417.

Fama, E.F. and French, K.R. (1988) Permanent and temporary components of stock prices, Journal of Political Economy, 96, 246-273.

Hong, H., Torous, W. and Valkanov, R. (2007) Do industries lead stock markets?, Journal of Financial Economics, 83, 367-396.

Kong, A., Rapach, D., Strauss, J., Tu, J. and Zhou, G. (2009) How predictable are components of the aggregate market portfolio?, Research Collection Lee Kong Chian School of Business.

Lo, A. W. and MacKinlay, A.C. (1988) Stock market prices do not follow random walks: evidence from a simple specification test, Review of Financial Studies, 1, 41-66.

Lo, A. W. and MacKinlay, A.C. (1990) When are contrarian profits due to stock market overreaction?, Review of Financial Studies, 3, 175-205. 
Mech, T.S. (1993) Portfolio return autocorrelation, Journal of Financial Economics, 34, 307344.

Menzly, L. and Ozbas, O. (2010) Market segmentation and cross-predictability of returns, Journal of Finance, 65, 1555-1580.

Poterba, J.M. and Summers, L.H. (1988) Mean reversion in stock prices: Evidence and implications, Journal of Financial Economics, 22, 27-59. 